
\title{
28 Research Square \\ Exploratory study of risk factors for congenital malformations in Morocco
}

\section{Khenata Forci ( $\nabla$ docteurforcikhenata@gmail.com )}

Universite Mohammed V de Rabat Faculte de Medecine et de Pharmacie Rabat https://orcid.org/00000003-2593-7249

\section{Mohamed Hassan Alami}

Universite Mohammed V de Rabat Faculte de Medecine et de Pharmacie Rabat

\section{El Arbi Bouaiti}

Universite Mohammed V de Rabat Faculte de Medecine et de Pharmacie Rabat

\section{Meriem Slaoui}

Universite Mohammed V de Rabat Faculte de Medecine et de Pharmacie Rabat

\section{Asmaa Mdaghri Alaoui}

Universite Mohammed V de Rabat Faculte de Medecine et de Pharmacie Rabat Amal Thimou Izgua

Universite Mohammed V de Rabat Faculte de Medecine et de Pharmacie Rabat

\section{Research article}

Keywords: Congenital malformation, risk factors, antenatal diagnosis, prevention, Morocco

Posted Date: June 30th, 2020

DOI: https://doi.org/10.21203/rs.3.rs-39095/v1

License: (c) (1) This work is licensed under a Creative Commons Attribution 4.0 International License.

Read Full License 


\section{Abstract}

Background: The aim of the study is to describe the teratogenic risk factors of congenital malformations in a large sample from the Moroccan population.

Methods: It is a descriptive epidemiological study conducted between January $1^{\text {st }}, 2011$ and June $31^{\text {th }}$, 2016 at the "Les Orangers" maternity and reproductive health hospital in Rabat, Morocco.

The data were collected on pre-established sheets and on the hospital's malformations register.

Results: A total of 245 cases of congenital malformations were recorded out of a total of 43923 births with a prevalence of 5.58 per thousand.

Women over 35 years represent $24.1 \%$ of all cases. Consanguinity was found in $22.4 \%$ of cases, maternal diabetes in $7 \%$, Fenugreek and herbs intake in $28.6 \%$, and medication in $2.8 \%$. Almost all of women $(97.5 \%)$ are of low to moderate socio-economic level. Antenatal diagnosis was performed in only $28.6 \%$ of cases.

Conclusion: Causes and risk factors of congenital malformations are diverse, which requires the application of large preventive and therapeutic approaches. However, the identification of risk factors specific to each country is necessary to establish specific preventive measures.

\section{Background}

Congenital malformations (CM) are a group of various prenatal disorders that might be caused by single gene abnormalities, chromosomal disorders, multiple heritable factors, environmental teratogens, or micronutrient deficiencies. In low and middle-income countries, some maternal infectious diseases, such as syphilis or rubella, are a major cause of congenital malformations. Furthermore, maternal diseases, such as diabetes, epilepsy, some particular medical conditions, such as iodine or folic acid deficiencies, exposure to drugs and recreational drugs, including alcohol and tobacco, and environmental chemicals and high dose radiation are other factors causing $\mathrm{CM}$.

Despite the progress made in molecular biology and imaging, 50\% of $\mathrm{CM}$ are of unknown etiology [1]. The causes of malformations in humans can be divided into three groups: [2]

- Genetic causes:

- Chromosomal aberrations in $10-15 \%$,

- Mendelian inheritance: 2-10\%

- Environmental causes:

- Maternal / placental infections (rubella, toxoplasmosis, syphilis, human immunodeficiency virus (HIV), cytomegalovirus (CMV), ...): 2-3\%

- Maternal pathology (diabetes, phenylketonuria, ...): 6-8\% 
- Drugs and chemical agents (alcohol, androgen, Phenytoin, Thalidomide, 13 cis retinoic acid, ...): 1\%

- Irradiation: $1 \%$

- Multifactorial causes: $20-25 \%$

- Unknown causes: $40-60 \%$

In developing countries, $\mathrm{CM}$ are not a public health priority. In our country, routine antenatal screening for malformations is not widespread and there is still no national register of all CM cases. In addition, at the national level, no studies have been conducted to determine the prevalence of these anomalies neither their causes nor associated risk factors.

For that, the identification of $\mathrm{CM}$ causes and risk factors is necessary to adapt prevention strategies and to target the suspected factors.

The objective of our study is to describe the teratogenic risk factors of $\mathrm{CM}$ in the Moroccan population.

\section{Methods}

\section{Study design}

The study was run from January $1^{\text {st }}, 2011$ to June $31^{\text {th }}, 2016$ at the "Les Orangers" maternity and reproductive health hospital in Rabat (HMSRO). This hospital is a level 3 structure with an average of 8000 deliveries per year.

This study included all pregnant women whose fetuses or newborns have one or more malformations detected by antenatal ultrasound and / or discovered on clinical examination at birth, regardless of the term or outcome of the pregnancy.

Parents were informed about the terms and objectives of the study and their consent was obtained.

Cases of refusal to participate in the survey were excluded as were the cases where the malformation was suspected on obstetrical ultrasound but was invalidated at birth.

Thus, we define: [3]

- Live birth: it is the expulsion or extraction, from the mother's body, of a conception product weighing $\geq$ $500 \mathrm{grs}$ (or $\geq 22 \mathrm{WA}$ ) which after this separation breathes, or has any other sign of life, such as heart beating, umbilical cord pulsation or effective contraction of a muscle subjected to the action of the will, whether the cord was cut or not.

- Fetal death: spontaneous cessation of fetal cardiac activity at a gestational stage greater than 14 weeks of amenorrhea. It can occur before labor = antepartum fetal death or intra-uterine fetal death, or during labor $=$ intrapartum fetal death or perpartum death. 
- A premature newborn: if born before 37 weeks of gestation.

- Full term newborn: from 37 to less than 42 full weeks (259 to 293 days) of gestation.

- Intrauterine Growth Restriction (IUGR): when the fetal birth weight is below the lower limit of the norm that is the 10th percentile of the reference curves.

\section{Data collection}

After informing parents about the objectives of our study and obtaining their informed consent, one of the participating doctors collects data about:

- Socio-economic and biodemographic anamnestic parameters of mothers,

- Consanguinity,

- History of malformation in the family or siblings,

- Maternal serology,

- Characteristics of pregnancy and childbirth (follow-up, pregnancy, mode of delivery, term of delivery),

- The possible exposure to teratogenic products (taking drugs and plants or contact with toxic products, habitat close to an industrial factory ....) and the time of exposure during pregnancy.

- Newborn data.

Data were recorded by the doctor who examines the newborn in collaboration with the pediatrician, on pre-established sheets and on the malformations' register of the HMSRO.

\section{Statistical analysis}

It is a descriptive epidemiological study. Data entry and statistical analysis were performed by SPSS 18.0 software. Qualitative variables were expressed in numbers and percentages, and quantitative variables in mean and standard deviation.

\section{Results}

During the study period, 245 cases of CM were diagnosed out of a total of 43923 births. The total prevalence was 5.58 per thousand births ( 55.78 per 10,000 births).

\section{Sociodemographic and obstetrical characteristics of mothers:}

The average gestationality was 2.39 with extremes of 1 to 8 and the average parity was 1.83 with extremes of 0 to 6 . About $37.1 \%$ of women were primiparous, while $37.6 \%$ were pauciparous and $25.3 \%$ were multiparous. 
Low socio-economic level was described in $70 \%$ of women. At the medical level, $73 \%$ of women have followed their pregnancy.

Rubella and toxoplasmosis immune status was unknown in half of women. Only one positive case of HIV and one case with positive syphilitic serology were identified.

Folic acid supplementation during pregnancy was noted in $27 \%$ of cases.Mean gestational age was $36.80 \pm 5.11$ weeks of amenorrhea.

A medical termination of pregnancy was performed in $5.3 \%$ of cases. $70.6 \%$ of women gave birth naturally, and $29.4 \%$ delivered by caesarean section.

Fetal death in utero (FDIU) was reported in $19.2 \%$ of cases, while IUGR was described in $12.7 \%$ of cases. Preterm delivery and full term birth were noted in $13.1 \%$ and $73 \%$ of cases, respectively.

Prenatal diagnosis was performed in $28.6 \%$ of cases; of which $5.7 \%$ ( 4 cases) in the first trimester, $47 \%$ (33 cases) in the second trimester, and $48.5 \%$ (34 cases) in the third trimester. Whereas in more than two thirds of cases $(71.4 \%)$ the diagnosis was made at birth during a systematic clinical examination of the newborn.

All the sociodemographic and obstetrical data of mothers are summarized in Table 1.

\section{Risk factors associated with congenital malformations:}

The mean age of mothers was $30.38 \pm 6.88$ with extreme ages of 16 and 48 years. Women aged over 35 years represent $24.1 \%$ (59 women), of whom almost one third gave birth to newborns with Down syndrome.

Consanguinity was noted in $22.4 \%$ of $\mathrm{CM}$ cases, of which $74.5 \%$ were related to first degree consanguinity.

$\mathrm{CM}$ history was noted in the siblings and in the family in $5.7 \%$ and $4.5 \%$ of the cases, respectively. Moreover, complications during pregnancy including diabetes were noted in $7 \%$ of cases.

Consumption of Fenugreek during pregnancy was noted in 46 cases (18.8\%), of which 11 cases (24\%) had neurological abnormalities such as anencephaly $(63 \%)$, hydrocephalus $(27 \%)$ and holoprosencephaly $(10 \%)$. The intake of various plants was found in $9.8 \%$ of cases, while the drug intake was noted in $2.8 \%$ (Table: 2).

\section{Discussion}

Although in almost half of congenital anomalies no specific cause is established, still there is a number of well-known risk factors [4]. 
In our study, the rate of women over 35 years represents one quarter of cases. However, it has been reported in the literature that the risk of CM is higher after the age of 35 years.

In general, as a literature review by Khoshnood reports, the prevalence of chromosomal and nonchromosomal abnormalities increases with maternal age [5]. This finding has contributed to the recommendation of routine prenatal screening in women over 35 years old.

In the present study, we have recorded 35 cases of trisomy 21 cases, which corresponds to $14.3 \%$ of all cases with $\mathrm{CM}$.

Half of Trisomy 21 cases were born to mothers over the age of 35 years. Indeed, advanced maternal age increases the risk of chromosomal abnormalities, particularly Down syndrome, as reported by Hook's study that shows a rate of 2 per 1000 for the lowest maternal ages, 2.6 for 1000 to 30 years, 5.6 for 1000 to 35 years, 15.8 for 1000 to 40 years and 53.7 for 1000 to 45 years [6]. Nevertheless, the risk of several $\mathrm{CM}$ exists even among young women. For this reason, in Canada, the Society of Obstetricians and Gynecologists of Canada (SOGC) recommends prenatal screening for fetal aneuploidy to all pregnant women regardless of age [7].

In our study the percentage of consanguinity is $22.4 \%$ of which three quarters $(74.5 \%)$ of the cases are first degree0. In fact, consanguinity increases the risk of heart, brain, and other genetic disorders [8]; it increases the prevalence of rare genetic congenital abnormalities by doubling the risk of newborn and infant death, intellectual disability, and other congenital anomalies when the parents are first cousins.

Some ethnic communities, such as Ashkenazi Jews or Finns, have a relatively high prevalence of rare genetic mutations with an increased risk of $\mathrm{CM}$.

A UK survey conducted between 2007 and 2010 on 11,300 newborns in the city of Bradford that includes a large Pakistani community characterized by a high percentage of consanguineous marriages concluded that the risk of $\mathrm{CM}$ goes from $3 \%$ when parents are not related to $6 \%$ when parents are cousins [8]. In turkey, a study have reported a rate of $23.2 \%$ of consanguinity among parents of children with $\mathrm{CM}$ [9].

Family history of $\mathrm{CM}$ has been significantly associated with the risk of $\mathrm{CM}$ in several series such as Shawky's study, which reported a family history of CM in $16.69 \%$ of cases [10]. In our series, the rate was $10.2 \%$.

In $94 \%$ of cases, severe $\mathrm{CM}$ occur in low- and middle-income countries where the mothers are exposed to malnutrition and infectious agents or teratogenic products that may induce abnormal prenatal development [4]. In our series, $97.5 \%$ of women are of low to moderate socio-economic status.

Maternal infections such as syphilis, rubella, toxoplasmosis and cytomegalovirus and HIV infections are a major cause of $\mathrm{CM}$ in low- and middle-income countries. 
In the present study:

- Rubella serology was performed in $47.7 \%$ of women of whom $26.9 \%$ were immunized.

- Toxoplasmosis serology was made in $51.8 \%$, of which only $15.9 \%$ were immunized.

- Syphilitic serology was determined in $62 \%$ of cases with a single case of evolutionary infection found in the context of clubfoot.

- Hepatitis serology was only performed in $17.6 \%$ of cases for hepatitis B and $14 \%$ for hepatitis C.

- HIV serology was investigated in $12.6 \%$ and was positive in one case with Down syndrome.

Although the link between maternal infections and the occurrence of $\mathrm{CM}$ is confirmed, in our context, serology investigations are not systematically run due to the lack of prenatal and pre-conception consultations by women, which make our interpretation of the collected results very complicated. Also, it explains the unknown immune status of almost the half of our cases.

It is well-known that nutritional deficiencies are related to certain congenital anomalies. For example, folate deficiency increases the risk of neural tube defects in the newborn, and excessive vitamin A intake may affect the normal development of the embryo or fetus. However, in our series, folic acid supplementation was noted in only $27 \%$ of cases.

Overweight and unbalanced diabetes increase the risk of birth defects. Indeed, several studies based on patient registers or cohort studies have reported an increased risk of malformations in the context of diabetes. A literature review, conducted between 1990 and 2005, have analyzed the teratogenicity of diabetes during pregnancy, found that the risk of CM in diabetes was increased [11, 12]. In our study, diabetes was found in $7 \%$ of malformation cases, a rate that is similar to that reported in Egypt (7.28\%) [10].

In our context, the intake of Fenugreek and plants during pregnancy was found in $28.6 \%$. Fenugreek (Trigonella foenum-graecum) is a plant widely cultivated in the Mediterranean area, India and China. Its grains are commonly consumed for the management of diabetes and hypercholesterolemia. It is used as a spice in Indian (curry), African and Moroccan cuisine.

A study conducted by Skalli from the Moroccan Center of Pharmacovigilance reported the occurrence of $\mathrm{CM}$ such as hydrocephalus and spina bifida after ingestion of fenugreek during pregnancy [13].

Another study in mice exposed to a high dose of fenugreek seeds concluded that exposure to fenugreek is responsible for the appearance of microcephaly probably due to abnormal proliferation of neurons and glial cells with significant stunted growth and impaired motor performance [14]. Kassem and al. observed a significant reduction in fetal and placental weight at 20 days of gestation, suggesting an embryo-fetal toxicity [15]. Fenugreek extract causes intrauterine growth retardation and impairs brain development at the doses of 500 and $1000 \mathrm{mg} / \mathrm{kg}$ per day [16]. 
Exposure to alcohol, tobacco or radiation during pregnancy increases the risk of having a fetus or newborn affected by CM. Working or living near or outside landfills, blast furnaces or mines is also a risk factor, especially if the mother is exposed to other environmental risk factors or suffers from nutritional deficiencies.

A case-control study conducted in Rhône-Alpes between 2001 and 2003 confirmed the presence of a link between the risk of the urinary tract malformations and exposure to emissions from municipal mass burn incinerators and that this risk is increased for mothers exposed to dioxins above a certain threshold in early pregnancy [17]. In our context, no case of contact with teratogenic agents has been reported because the hypothesis of environmental pollution has not been explored.

In our study, drug intake; including paracetamol, acetyl salicylic acid, corticosteroids, antiretrovirals and antiepileptics; was noted in $2.8 \%$.

Studies have shown that the use of acetyl salicylic acid at low doses of 50-150 mg/day in the prevention of preeclampsia is teratogenic in rodents, monkeys, dogs and cats. Also, it induces neural tube closure abnormalities, skeletal abnormalities and cleft palates. At the doses of 250 and $1000 \mathrm{mg} / \mathrm{kg}$, miscarriage and FDIU are induced [18].

In humans, studies have shown that taking aspirin in the first trimester causes congenital heart defects [19] and gastroschisis [20, 21, 22]. However, epidemiological data did not show an association between taking aspirin in the first trimester and increasing the rate of CM [23].

At high dose during the $2^{\text {nd }}$ trimester of pregnancy, aspirin may cause premature closure of the ductus arteriosus with pulmonary hypertension and renal effects and intracerebral fetal hemorrhage $[24,25,26$, 27]. In fact, all NSAIDs (nonsteroidal anti-inflammatory drugs) can lead to cardiac and / or renal fetal and / or neonatal toxicity, sometimes irreversible or even fatal [28].

Regarding corticosteroids intake, case-control studies have shown an increased risk of cleft lip or labiopalatine and IUGR when taking corticosteroids orally [29].

In our study, a case of short limb was identified in a woman who had taken corticosteroids associated with acetyl salicylic acid as part of Pemphigoid gestationis treatment.

Antiretrovirals were only taken by one case of HIV-positive mother put on treatment at the beginning of the pregnancy, which gave birth to a new born with Down syndrome.

A preliminary analysis of an observational study of 426 neonates conducted in Botswana in 2018 raised the risk of neural tube closure abnormality in 4 of the neonates of mothers treated with a combination of antiretrovirals with an incidence of $0.9 \%$ [30]. Other studies have shown an increased risk of congenital heart disease [31], skin and musculoskeletal abnormalities [32]. 
Paracetamol intake was noted in three cases in our series; a case of hydrocephalus, a case of myelomeningocele, and a clubfoot case.

However, several studies have reported that Paracetamol exposure during pregnancy may result in developmental alterations both in the brain with behavioral disorders and hyperactivity, and autism spectrum symptoms and paracetamol for more than 4 weeks during the first and second trimesters of pregnancy may increase the frequency of cryptorchidism [33].

Sodium Valproate intake was reported by one mother who was followed for epilepsy and stopped her treatment at the beginning of the first trimester. The outcome of this pregnancy was marked by the occurrence of a chylothorax and the perpartum death of the newborn due to a severe respiratory distress.

According to the latest French report by ANSM (national agency of safety of the drug and health products) published in April 2019, the risk of malformation in case of valproic acid intake is multiplied by 4-5 compared to the general population. Besides, it's associated with the risk of occurrence of neural tube closure, oral cleft, hypospadias, facial dysmorphism, craniosynostosis, cardiac, renal, urogenital and limb malformations, and polymalformative syndromes [34].

The existence of neurodevelopmental disorders (development quotient / intelligence quotient decrease, developmental delays, autistic spectrum disorders) in children exposed in utero to valproic acid has been established regardless of the term of pregnancy and the administered dose, and these disorders are extremely severe and can lead to educational and professional disabilities. Data also suggest an increase in attention deficit disorder and hyperactivity.

\section{Limitations Of The Study}

- It is a descriptive study carried out in a single center,

- As in most of these studies, taking medication during pregnancy is not always specified.

- Poorly structured antenatal surveillance makes information about supplementation (iron, vitamins), serology, and antenatal diagnosis unavailable.

- In case of fetal death in utero, only X-rays and autopsy can inform about the malformation etiology.

- In order to notify all abnormalities including functional abnormalities, it is necessary to make a longterm follow-up, which was not the case in the present study.

\section{Conclusion}

Our study raises more problems than solutions; among which:

- Lack of awareness of pregnant women during pregnancy,

- Low rate of CM cases that are diagnosed prenatally, consequently, setting up a strategy for CM antenatal screening is needed. 
- The problem of CM national register that must be established,

- Lack of coordination with the Pharmacovigilance Center, hence the importance of creating a teratovigilance network able to communicate all statistical data permanently.

As a result, a systematized policy in the context of $\mathrm{CM}$ must be urgently implemented.

\section{Tables}

Table 1: Sociodemographic and obstetrical characteristics of malformed newborns'mothers at the HMSRO, Rabat, Morocco 


\section{Number of cases Percentage \%}

\section{Marital status}

Married

241

98.4

Not married

4

1.6

Profession

Housewife

229

93.5

Working mother

16

6.5

\section{Socio-economic level}

Low

172

70.2

Middle

67

27.3

High

5

2

Unknown

1

0.4

\section{Medical history}

Diabetes

Gestational Diabetes

Malformed foot

0.4

Malformed uterus

0.4

Epilepsy

1

0.4

Depressive disorders

1

0.4

Hypothyroidisim

1

0.4

Family diabetes

16.7

\section{Gestational age}

$<22$ WA

${ }^{3} 37$ WA

176

73

\section{Parity}

Primiparous

91

37.1

Pauciparous

92

37.6

Multiparous

62

25.3

Pregnancy follow-up 


\begin{tabular}{|c|c|c|}
\hline No follow-up & 23 & 9.4 \\
\hline Well follow-up & 179 & 73.1 \\
\hline Poor follow-up & 43 & 17.6 \\
\hline \multicolumn{3}{|l|}{ Prenatal diagnosis } \\
\hline Not done & 175 & 71.4 \\
\hline Done & 70 & 28.6 \\
\hline at $\mathrm{T} 1$ & 4 & 1.6 \\
\hline at T2 & 33 & 13.5 \\
\hline at T3 & 34 & 13.9 \\
\hline \multicolumn{3}{|l|}{ Mode of delivery } \\
\hline Normal & 173 & 70.6 \\
\hline Caesarean section & 72 & 29.4 \\
\hline TIP & \multirow[t]{2}{*}{13} & 5.3 \\
\hline \multicolumn{2}{|c|}{ Outcome of pregnancy } & \\
\hline FDIU & \multirow[t]{2}{*}{47} & 19.2 \\
\hline TIP & & \\
\hline IUGR & 31 & 12.7 \\
\hline Early-term delivery & 32 & 13.1 \\
\hline Full-term delivery & 176 & 73 \\
\hline
\end{tabular}

WA: weeks of amenorrhea, T: trimester, FDIU: Fetal death in-utero, TIP: Therapeutic interruption of pregnancy,

IUGR: Intrauterine Growth Restriction

Table 2: Risk factors associated with CM in malformed newborns'mothers at the HMSRO, Rabat, Morocco 


\begin{tabular}{|c|c|c|c|}
\hline \multicolumn{3}{|c|}{ Number of cases } & \multirow[t]{2}{*}{ Percentage \% } \\
\hline \multicolumn{3}{|l|}{ Age } & \\
\hline \multicolumn{2}{|l|}{$<35$ ans } & 186 & 75.9 \\
\hline \multicolumn{2}{|l|}{ 335ans } & 59 & 24.1 \\
\hline \multicolumn{4}{|l|}{ Consanguinity } \\
\hline \multicolumn{2}{|l|}{ Absence } & 190 & 77.6 \\
\hline \multicolumn{2}{|l|}{ Presence } & 55 & 22.4 \\
\hline \multirow[t]{3}{*}{ Degree } & 1 & 41 & 74.5 \\
\hline & 2 & 10 & 18.2 \\
\hline & 3 & 4 & 7.3 \\
\hline \multicolumn{2}{|c|}{ Malformation history in siblings } & 14 & 5.7 \\
\hline \multicolumn{2}{|c|}{ Malformation history in family } & 11 & 4.5 \\
\hline \multicolumn{2}{|c|}{ Complications during pregnancy } & 44 & 18 \\
\hline \multicolumn{2}{|l|}{ Diabetes } & 7 & 2.9 \\
\hline \multicolumn{2}{|c|}{ Gestationnal diabetes } & 10 & 4.1 \\
\hline \multicolumn{2}{|l|}{ Anemia } & 6 & 2.4 \\
\hline \multicolumn{2}{|l|}{ HIV } & 1 & 0.4 \\
\hline \multicolumn{2}{|l|}{ Hypothyroidism } & 1 & 0.4 \\
\hline \multicolumn{2}{|c|}{ Pemphigoid gestationis } & 1 & 0.4 \\
\hline \multicolumn{2}{|l|}{ Syphilis } & 1 & 0.4 \\
\hline \multicolumn{2}{|c|}{ Fenugreek consumption } & 46 & 18.8 \\
\hline \multicolumn{2}{|l|}{ TO } & 4 & 1.6 \\
\hline \multicolumn{2}{|l|}{$\mathrm{T} 1$} & 35 & 14.3 \\
\hline \multicolumn{2}{|l|}{$\mathrm{T} 2$} & 18 & 7.3 \\
\hline \multicolumn{2}{|l|}{ T3 } & 25 & 10.2 \\
\hline \multicolumn{2}{|c|}{ Other plants consumption } & 24 & 9.8 \\
\hline \multicolumn{2}{|l|}{ TO } & 3 & 1.2 \\
\hline \multicolumn{2}{|l|}{$\mathrm{T} 1$} & 19 & 7.8 \\
\hline \multicolumn{2}{|l|}{$\mathrm{T} 2$} & 7 & 2.9 \\
\hline \multicolumn{2}{|l|}{ T3 } & 6 & 2.4 \\
\hline
\end{tabular}




$\begin{array}{lll}\text { Medication } & 7 & 2.8 \\ \text { Paracetamol } & 3 & 1.2 \\ \text { Acetylsalicilic acid } & 1 & 0.4 \\ \text { Corticoids } & 1 & 0.4 \\ \text { Aluviq+ Duovir (AZT) } & 1 & 0.4 \\ \text { Sodium Valproate } & 1 & 0.4 \\ \text { Toxic habits } & 0 & \end{array}$

HIV: Human Immunodeficiency virus, T: trimester, TO: pre-conception period, AZT: Azidothymidin

\section{Abbreviations}

CM: Congenital malformations

HIV: Human immunodeficiency virus

CMV: Cytomegalovirus

HMSRO: "Les Orangers" maternity and reproductive health hospital in Rabat

WA: weeks of amenorrhea

IUGR: Intrauterine Growth Restriction

FDIU: Fetal death in utero

SOGC: Society of Obstetricians and Gynecologists of Canada

NSAIDs: nonsteroidal anti-inflammatory drugs

ANSM: National Agency of Safety of the Drug and Health Products)

\section{Declarations}

\section{Ethics approval and consent to participate}

The Ethical Committee of Biological Research, Faculty of Medicine and Pharmacy - Rabat, approved the study. Oral consent to participate was obtained from the parents.

\section{Consent for publication}

The consent for publication was obtained from the parents. 


\section{Data availability}

Data are available upon reasonable request to the first co-author

\section{Competing interests}

All the authors declare that they have no competing interests

\section{Funding}

Not applicable

\section{Authors'contributions}

ATI was responsible for the study concept and design. KF coordinated the study and interviewed the parents. KF and EB analyzed the data. KF led the drafting of this manuscript, with input from all authors. ATI and MHA supervised analysis of the data and contributed to the writing. MS contributed to the revision of English. ATI, MHA, EB, MS and AMA contributed to revision and final approval of the manuscript.

All the authors have approved the present version of the manuscript.

\section{Acknowledgments}

We would like to thank everyone who had contributed in this study.

\section{References}

1. Pathologie du développement: malformations congénitales 2011-2012. Collège Français des Pathologistes (CoPath).

2. Stevenson RE et collaborateurs (Edit). Human Malformations and Related Anomalies. New York. Oxford University Press, 1993, p 115

3. CIM-10 FR, classification statistique internationale des maladies et des problèmes de santé connexes. Rapport de la conference internationale, volume 1, édition 2017

4. Anomalies congénitales: OMS (Aide-mémoire) N³70, Avril 2015

5. Khoshnood, M.-H. Bouvier-Colle, H. Leridon, B. Blondel. Impact de l'âge maternel élevé sur la fertilité, la santé de la mère et la santé de l'enfant. Journal de Gynécologie Obstétrique et Biologie de la Reproduction, Volume 37, $\mathrm{n}^{\circ}$ 8, pages 733-747 (décembre 2008) https://doi.org/10.1016/j.jgyn.2008.08.007

6. Hook E.B. Rates of chromosome abnormalities at different maternal ages. ObstetGynecol 1981; 58 : $282-285$ 
7. Dr Gregory Taylor. Les anomalies congénitales au CANADA 2013, Rapport de surveillance sur la santé périnatale. Agence de la santé publique du CANADA, Ottawa, Septembre 2013

8. Eamonn Sheridan, John Wright, Neil Small, Peter C Corry, Sam Oddie, Catherine Whibley, et al.Risk factors for congenital anomaly in a multiethnic birth cohort: an analysis of the Born in Bradford THE LANCET, volume 382, №9901, p 1350-1359, Octobre 2013 http://doi.org/10.1016/S01406736(13)61132-0

9. DEMIREL S., KAPLANOGLU N., ACAR A., BODUR S., PAYDAK F. The frequency of consanguinity in Konya, Turkey, and its medical effects. Couns. $1997 ; 8: 295-301$

10. Shawky, Doaa I. Sadik. Congenital malformations prevalent among Egyptien children and associated risk factors. The Egyptian Journal of Medical Human Genetics (2011) 12, 69-78

11. Mitanchez D. Complications foetales et néonatales du diagnostic gestationnel: mortalité périnatale, malformations congénitales, macrosomie, dystocie des épaules, traumatisme obstétrical. J GynecolObstetBiolReprod (Paris) 2010; 39:189-99.

12. Allen VM, Armson BA, Wilson RD, Allen VM, Blight $C$, Gagnon A,et al. Teratogenicity associated with preexisting and gestational diabetes. J ObstetGynecol Can 2007; 29:927-34.

13. Skalli S. Malformations associées à la prise de fenugrec au cours de la grossesse. Bulletin d'informations de pharmacovigilance 3, 2006.

14. Khalki L, Bennis M, Sokar Z, Ba-M'hamed S. The developmental neurobehavioral effects of fenugreek seeds on prenatally exposed mice. J Ethnopharmacol 2012; 139:672-

7. http://doi.org/10.1016/j.jep.2011.12.011

15. Kassem A, Al-Aghbaria A, Al-Haborib M, Al-Mamary M. Evaluation of the potential antifertility effect of fenugreek seeds in male and female rabbits. Contraception. 2006; 73: 3016. http://doi.org/10.1016/j.contraception.2005.08.020

16. Khalki L, Bam'hamed S, Bennis M, Chait A, Sokar Z. Evaluation of the developmental toxicity of the aqueous extract from trigonellafoenum-graecum in mice. $J$ Ethnopharmacol 2010;131:321-

5. http://doi.org/10.1016/j.jep.2010.06.033

17. Cordier, A. Lehébel, E. Amar, L. Anzivino-Viricel, M. Hours, C. Monfort, and al. Maternal residence near municipal waste incinerators and the risk of urinary tract birth defects. Occupational and Environmental Medicine. 2010, vol 67, n7, p. 493-99. http://doi.org/10.1136/oem.2009.052456

18. Serreau. Médicaments utilisés dans la prise en charge de la prééclampsie: Pharmacologie et risque fœtaux. Annales Françaises d'Anesthésie et de Réanimation 29 (2010) e37-e46

19. Werler MM, Mitchell AA, Shapiro S. The relation of aspirin use during the first trimester of pregnancy to congenital cardiac defects. N Engl J Med 1989; 321:1639-

42. http://doi.org/10.1056/NEJM198912143212404

20. Torfs CP, Katz EA, Bateson TF, Lam PK, Curry CJR. Maternal Medications and Environmental Exposures as Risk Factors for Gastroschisis. Teratology, 1996; 54:8492. http://doi.org/10.1002/(SICI)1096-9926(199606)54:2<84::AID-TERA4>3.0.C0;2-4 
21. Martinez-Frias M, Rodriguez-Pinilla E, Prieto L. Prenatal Exposure to Salicylates and Gastroschisis: A Case-Control Study. Teratology 1997; 56:241-3. http://doi.org/10.1002/(SICl)10969926(199710)56:4<241::AID-TERA2>3.0.C0;2-1

22. Drongowski RA, Smith Jr RK, Coran AG, Klein MD. Contribution of demographic and environmental factors to the etiology of gastroschisis: a hypothesis. Fetal DiagnTher. 1991; 6:14-27. http://doi.org/ $10.1159 / 000263620$

23. Slone D, Siskind V, Heinonen OP, Monson RR, Kaufman DW, Shapiro S. Aspirin and congenital malformations. Lancet 1976; 1:1373-5.

24. Lewis RB, Schulman JD. Influence of acetylsalicylic acid, an inhibitor of prostaglandin synthesis, on the duration of human gestation and labour. Lancet 1973; 2:1159-61. http://doi.org/10.1016/s01406736(73)92934-6

25. Levin DL, Fixer DE, Morris FC, Tyson J. Morphologic analysis of the pulmonary vascular bed in infants exposed in utero to prostaglandin synthetase inhibitors. J Pediatr. 1978; 92:47883. http://doi.org/10.1016/s0022-3476(78)80453-3

26. Rumack CM, Guggenheim MA, Rumack BH, Peterson RG, Johnson M, Braithwaite WR. Neonatal intracranial hemorrhage and maternal use of aspirin. ObstetGynecol 1981; 58:52S-6S.

27. Elisabeth ELEFANT, Françoise Bavoux, Catherine VAUZELLE-GARDIER, Faiza ASSARI-MERABTENE. Grossesse, medicaments, vaccins, et radiations, 2003 - medical78.com

28. Elisabeth Elefant, Marie-Pierre Cournot, Delphine Beghin, Catherine Vauzelle. Médicaments et grossesse en rhumatologie. Revue du rhumatisme 77S (2010) A1-A5

29. Carmichael SL, Shaw GM, Ma C, et al. Maternal corticosteroid use and orofacial clefts. Am J ObstetGynecol 2007; 197:585 e1-7 (discussion 683-4 e1-

7) http://doi.org/10.1016/j.ajog.2007.05.046

30. Philipe Morlat. Prise en charge médicale des personnes vivant avec le VIH, recommandations du groupe d'expert, Désir d'enfant et grossesse. (mai 2018).

31. Sibiude J, Le Chenadec J, Bonnet D, Tubiana R, Faye A, Dollfus C, et al. In Utero Exposure to Zidovudine and Heart Anomalies in the ANRS French Perinatal Cohort and the Nested PRIMEVA Randomized Trial. Clinical infectious diseases: an official publication of the Infectious Diseases Society of America. 2015; 61(2):270-80. http://doi.org/10.1093/cid/civ260

32. Williams PL, Crain MJ, Yildirim C, Hazra R, Van Dyke RB, Rich K, et al. Congenital anomalies and in utero antiretroviral exposure in human immunodeficiency virus-exposed uninfected infants. JAMA pediatrics. 2015; 169(1):48-55. http://doi.org/10.1001/jamapediatrics.2014.1889

33. BAUDON Laurie-Anne. Les risques de l'exposition prénatale au Paracétamol. Thèse, année 2018, Université de Bordeaux U.F.R. DES SCIENCES PHARMACEUTIQUES

34. Cyndie Picot, Antiépileptiques au cours de la grossesse : Etat actuel des connaissances sur le risque de malformations et de troubles neuro-développementaux, Synthèse, Rapport d'Avril 2019 de l'ANSM (agence nationale de sécurité du médicament et des produits de santé) 